\title{
Estimating changes in ocean ventilation from early 1990s CFC-12 and late 2000s $\mathrm{SF}_{6}$ measurements
}

\author{
Toste Tanhua, ${ }^{1}$ Darryn W. Waugh, ${ }^{2}$ and John L. Bullister ${ }^{3}$ \\ Received 3 December 2012; revised 8 February 2013; accepted 12 February 2013; published 14 March 2013.
}

[1] Transient tracer measurements can constrain the rates and pathways of ocean ventilation and act as proxies for biogeochemically relevant gases such as $\mathrm{CO}_{2}$ and oxygen. Various techniques have deduced changes in ocean ventilation over decadal timescales using transient tracer measurements made on repeat sections, but these require a priori assumptions about mixing in the ocean interior. Here, we introduce a simple, direct observational method that takes advantage of the similar atmospheric increase rates of chlorofluorocarbon-12 and sulfur hexafluoride, but with a time lag (offset) of 14-15 years. Such repeat measurements can be directly compared without prior assumptions about mixing. A difference larger than $\sim 2$ years between modern sulfur hexafluoride and historical chlorofluorocarbon-12 tracer ages implies a change in ventilation, although lack of difference does not necessarily imply no change. Several tracer data sets are presented, which suggest changes in ventilation in the South Pacific and North Atlantic Oceans. Citation: Tanhua, T., D. W. Waugh, and J. L. Bullister (2013), Estimating changes in ocean ventilation from early 1990s CFC-12 and late 2000s SF 6 measurements, Geophys. Res. Lett. 40, 927-932, doi:10.1002/grl.50251.

\section{Introduction}

[2] The age of a water mass quantifies the time since it was last in contact with the surface of the ocean, where it could equilibrate with atmospheric gases, such as oxygen and $\mathrm{CO}_{2}$. Ventilation is a critical process to propagate surface perturbations to the interior ocean and is relevant to, for example, the sequestration of anthropogenic carbon [Waugh et al., 2006] or for quantifying the in situ production of $\mathrm{N}_{2} \mathrm{O}$ [Freing et al., 2009]. Ventilation rates and pathways can be empirically determined using measurements of transient tracers such as chlorofluorocarbons (CFCs). Furthermore, repeat measurements of transient tracers on multiyear basis allows for quantification of changes in ocean ventilation from direct observations. Various methods and models have been developed to calculate the "age" of a water parcel based on transient tracer data. This is, however, not straightforward due to the nonlinear atmospheric histories of most of the commonly used tracers and to mixing in the ocean interior. Thus, even relatively large changes in tracer-derived ages for different years of observation does not necessarily

\footnotetext{
${ }^{1}$ GEOMAR Helmholtz Centre for Ocean Research Kiel, Kiel, Germany.

${ }^{2}$ Department of Earth and Planetary Sciences, Johns Hopkins University, Baltimore, Maryland, USA.

${ }^{3}$ National Oceanic and Atmospheric Administration, Pacific Marine Environmental Laboratory, Seattle, Washington, USA.

Corresponding author: T. Tanhua, GEOMAR Helmholtz Centre for Ocean Research Kiel, Düsternbrooker Weg 20, 24105 Kiel, Germany. (ttanhua@geomar.de)

(C)2013. American Geophysical Union. All Rights Reserved. 0094-8276/13/10.1002/grl.50251
}

imply changes in transport as there can be significant variations in tracer ages from different years even for steady transport [e.g., Sonnerup, 2001; Waugh et al., 2003; Sonnerup et al., 2008]. Previous studies using tracer ages have had to make assumptions about, or use models of, ocean mixing to investigate temporal changes in the flow. In this article, we demonstrate a simple method, using a minimum of assumptions, to compare ventilation rates determined directly from "historical" CFC-12 measurements (i.e., those made in the early to mid-1990s) and "modern" sulfur hexafluoride $\left(\mathrm{SF}_{6}\right)$ measurements (i.e., those made in the mid- to late 2000s) made along repeat hydrography sections.

\section{Transient Tracers}

[3] CFCs and $\mathrm{SF}_{6}$ are anthropogenic gases that are released to the atmosphere from where they equilibrate with the surface waters of the world's ocean. The atmospheric time history of the CFCs and $\mathrm{SF}_{6}$ [Walker et al., 2000; Bullister, 2011] (Figure 1a) and the solubility dependence on salinity and temperature for CFC-11 and CFC-12 [Warner and Weiss, 1985] and $\mathrm{SF}_{6}$ [Bullister et al., 2002] are well established, which together with assumptions of the surface saturation defines the surface water history of the tracers at the ocean surface. The distribution of CFCs and $\mathrm{SF}_{6}$ in the ocean interior thus contain information of ocean ventilation. CFCs have been used as transient tracers in the ocean interior since the late 1970 s and is a standard parameter measured on WOCE/CLIVAR-style large-scale hydrographic cruises [e.g., Gammon et al., 1982; Fine, 2011]. However, the growth rate of CFCs (i.e., CFC-11, CFC-12, and CFC-113) in the atmosphere has slowed since the early mid-1990s and subsequently reversed. As a consequence, although CFCs will continue to be very useful as transient tracers on decade-tocentury timescales as they propagate into the thermocline and deep ocean, their usefulness as transient tracers for recently (since the mid-1990s) ventilated waters is reduced. $\mathrm{SF}_{6}$ is a tracer that was introduced later than the CFCs to the atmosphere but has a steadily increasing concentration which makes $\mathrm{SF}_{6}$ particularly useful for dating recently ventilated waters [e.g., Tanhua et al., 2008]. $\mathrm{SF}_{6}$ is somewhat less useful for dating "older" waters because currently the penetration of measurable concentrations of $\mathrm{SF}_{6}$ is significantly less that of CFC-12 in much of the ocean interior. $\mathrm{SF}_{6}$ has been increasingly used as a transient tracer [e.g., Law and Watson, 2001; Tanhua et al., 2004] and is becoming a standard variable to measure together with the CFCs on hydrographic cruises [e.g., Bullister and Wisegarver, 2008].

\section{Age Concepts}

[4] In the very simplest method, to determine a timescale or age from tracers, the partial pressure of the tracer (e.g., pCFC12 or $\mathrm{pSF}_{6}$ ) in the interior ocean is matched with the atmospheric time history (Figure 1a). This is known by a 

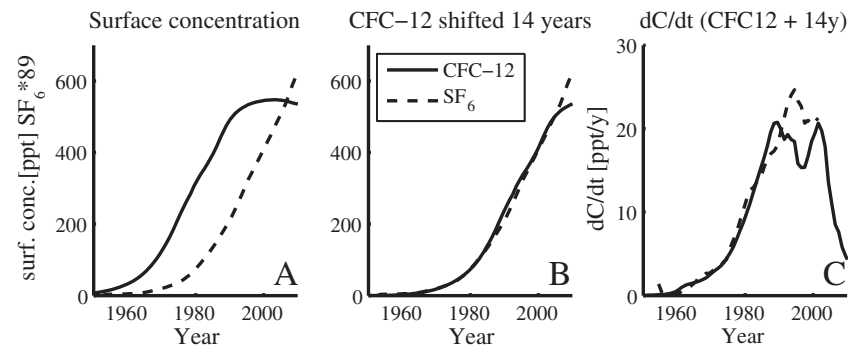

Figure 1. (A) Time series of the northern hemisphere surface concentrations (expressed as partial pressure in parts per trillion) of CFC-12 (solid) and $\mathrm{SF}_{6}$ (dashed) in equilibrium with the atmosphere. (B) The CFC-12 curve is shifted +14 years to demonstrate the similarities of the two curves. (C) The growth rate of $\mathrm{SF}_{6}$ and $\mathrm{CFC}-12$ (shifted 14 years). The $\mathrm{SF}_{6}$ concentrations are scaled by a factor of 89 in all panels.

variety of names, including pCFC age, apparent age, or tracer age. This method is conceptually simple but implicitly assumes purely advective flow, that is, mixing in the interior ocean is ignored. This assumption, together with the nonlinear atmospheric growth rate of the tracers, results in different tracer ages for different transient tracers applied on the same water sample, and significant temporal variations in tracer ages can occur over time even in the case of constant oceanic circulation [e.g., Sonnerup, 2001; Waugh et al., 2003]. This affects estimates of changes in circulation or ventilation in the ocean interior determined from repeat transient tracer measurements using tracer ages.

[5] These shortcomings can be overcome by applying the transit time distribution (TTD) model to the transient tracer observations [e.g., Hall and Haine, 2002; Waugh et al., 2003], realizing that with mixing, each water parcel in the ocean actually consists of a multitude of aliquots having a distribution of pathways and transit times to its location. They demonstrated that differences in ages derived from various tracers are a consequence of mixing and that these ages are fundamentally different from the true mean age, that is, the average age since a water sample was in contact with the atmosphere. The functional shape of the TTD is often approximated with an inverse Gaussian (IG) function, which is defined by two parameters, the mean age $(\Gamma)$ and the width $(\Delta)$. This has the advantage that the TTD can be estimated from simultaneous observations of multiple transient tracers with different atmospheric histories. The $\Delta / \Gamma$ ratio provides information on the relation between advection and diffusion of the circulation.

\section{The "Combined Historical CFC-12 and Modern SF 6 " Method}

[6] We introduce here a new method for examining temporal changes in the rate of ventilation that is based on the similarities in the atmospheric histories for $\mathrm{SF}_{6}$ and CFC-12, if a time lag is considered. More precisely, the nonlinearity of the atmospheric history of $\mathrm{SF}_{6}$ until at least 2010 is very similar to the CFC-12 history up to early 1990 s, and the normalized time series of these tracers closely match if one is shifted by approximately14 years (Figure 1b). This means that if the flow is in steady state, the $\mathrm{SF}_{6}$ tracer age for measurements made in $\sim 2004$ for any location in the ocean will be very similar to the CFC-12 tracer age for measurements made at the same location in $\sim 1990$. This applies for all flows and TTDs, so that no assumptions of the flow need to be made. Thus, a difference between $\mathrm{SF}_{6}$ ( $\sim$ year 2004) and CFC-12 ( $\sim$ year 1990) tracer ages implies a change in transport. However, having the same age does not necessarily imply that the transport is invariant or steady.

[7] Before applying this method to field observations, we used modeled tracer ages to examine how closely $\mathrm{SF}_{6}$ tracer ages from a recent repeat hydrography cruise should resemble the CFC-12 tracer ages from an earlier cruise in a steadystate ocean. We first considered synthetically generated tracers using TTDs that are IG distributions and compared $\mathrm{CFC}-12$ and $\mathrm{SF}_{6}$ tracer ages for a wide range of the two moments of the IG function, $\Gamma$ and $\Delta$. As an example, Figure $2 \mathrm{a}$ plots the 1994 CFC-12 tracer age (i.e., CFC-12 age calculated from CFC-12 in 1994) against the $2008 \mathrm{SF}_{6}$ tracer age for $\Gamma$ varying between 5 and 150 years and $\Delta / \Gamma$ varying between 0.2 and 2.0 in the model. This shows that the tracer ages generally agree within \pm 1.5 years. The $\mathrm{SF}_{6}$ tracer age is somewhat smaller than the CFC-12 age for ages $\sim 10-20$ years, which can be related to small differences in the atmospheric time series, that is, the relative increase rate for CFC-12 during 1970-1980 is slightly different from that for $\mathrm{SF}_{6}$ during the 1985-2000 period (see Figure 1c). This small difference between "historical" (1990s) CFC-12 tracer ages and "modern" (late 2000s) $\mathrm{SF}_{6}$ tracer ages hold for a range of dates for the initial CFC-12 observations and time lags between the CFC- 12 and the $\mathrm{SF}_{6}$ observations. This can be seen in Figure 2b, which shows the root mean square difference/error between the tracer ages (over the same range of $\Gamma$ and $\Delta$ as in Figure 2a) as a function of the year of the initial CFC-12 observation and the time difference (time lag) between the CFC-12 and the subsequent $\mathrm{SF}_{6}$ observations. The minimum error occurs for $\mathrm{CFC}-12$ observations made in the time frame 1989-1992 and $\mathrm{SF}_{6}$ observations made with a 14-15 year time lag (which implies $\mathrm{SF}_{6}$ measurements during 2003-2006). However, the difference is still small for CFC-12 measurements between 1989 and 1996 with time lags of $12-16$ years. These IG TTD calculations indicate that an $\mathrm{SF}_{6}$ age observed in mid- to late $2000 \mathrm{~s}$ that is more than $\sim 2$ years different from a CFC-12 age from the early 1990s implies a statistically significant change in circulation/ventilation.

[8] As a second test, we examined CFC-12 and $\mathrm{SF}_{6}$ ages from transport simulations using the steady, data-assimilated, circulation model of DeVries and Primeau [2011]. This model is forced by climatological temperature, salinity, and ${ }^{14} \mathrm{C}$ data and has been used to estimate water mass ages in the ocean. Figures $2 \mathrm{C}$ and $2 \mathrm{D}$ show the relationships between 1994 CFC-12 tracer age and $2008 \mathrm{SF}_{6}$ tracer age for simulated $\mathrm{CFC}-12$ and $\mathrm{SF}_{6}$ in the North Atlantic (Figure 2C) and South Pacific (Figure 2D). As for the TTDgenerated tracers, there is good agreement between the historical CFC-12 and the modern $\mathrm{SF}_{6}$ tracer ages. This supports the hypothesis that historical CFC-12 and modern $\mathrm{SF}_{6}$ tracer ages agree in steady flows. Because the assimilation model does not assume an IG distribution of the TTD, this suggests that the "combined historical $\mathrm{CFC}-12$ and modern $\mathrm{SF}_{6}$ method" is relatively insensitive to the shape of the TTD.

[9] There is generally a strong dependence of surface saturation on the calculations of tracer ages in the ocean interior. The result of this analysis, however, remains valid even for different surface saturation for the two tracers, 

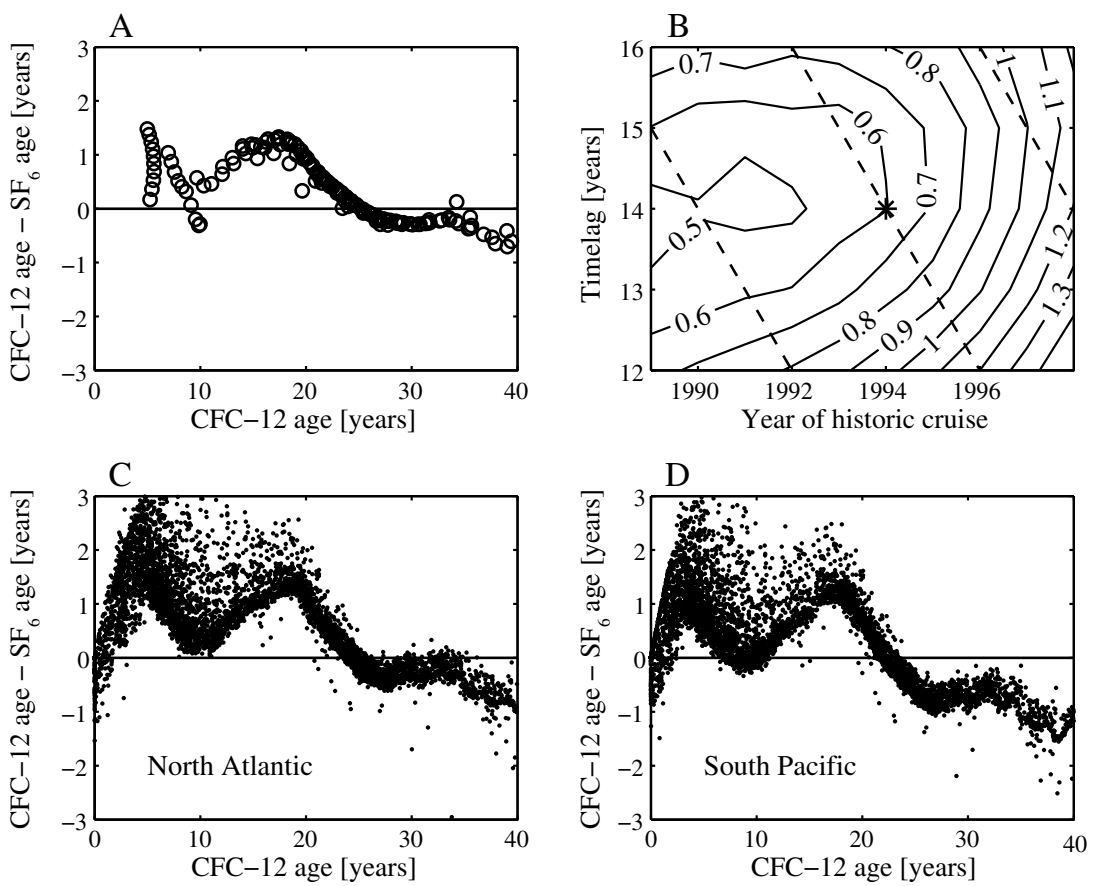

Figure 2. Biases and uncertainty of calculating the tracer age with $\mathrm{SF}_{6}$ and $\mathrm{CFC}-12$ data. (A) The difference between $\mathrm{SF}_{6}$ age (measured in 2008) and CFC-12 age (measured in 1993) using IG TTDs for a range of Gamma and Delta ratios (i.e., $\Delta / \Gamma$ varied from 0.2 to 2.0) and tracer ages. (B) Uncertainty (root mean square error, years) for a range of sampling years for the historic cruise (year 1), and time lags to the modern cruise. The dashed lines show fixed values for the modern cruise (2004, 2008, and 2012) and different years of the historic cruise (i.e., time lags). The asterisk marks the data shown in the upper panel. ( $\mathrm{C}$ and D) Same as panel A, except CFC-12 and $\mathrm{SF}_{6}$ are for locations in the north Atlantic Ocean (15 ${ }^{\circ} \mathrm{N}$ and $\left.45^{\circ} \mathrm{N}\right)$ and Southern Pacific Ocean $\left(15^{\circ} \mathrm{S}\right.$ and $\left.45^{\circ} \mathrm{S}\right)$ from the steady-state circulation model [DeVries and Primeau, 2011].

provided that the saturation of the two tracers is internally consistent with each other. However, differences in saturation between the two tracers reduces this similarity so that the optimal time lag of 14 years between cruises will change, unless the surface saturation is known and can be compensated for (which is mostly not the case). The surface saturation of tracers has been shown to be related to the depth of the mixed layer [Haine and Richards, 1995], and the increase rate in the surface saturation is likely influencing the surface saturation [e.g., Tanhua et al., 2008]. However, the transfer velocity over the air-sea interface and the increase rates for the two tracers $\mathrm{CFC}-12$ and $\mathrm{SF}_{6}$ are similar. In fact, the observational evidence of surface saturation suggests that the saturation of "modern" $\mathrm{SF}_{6}$ and "historic" CFC-12 has been similar.

\section{Ocean Data}

[10] We now apply our method for detecting changes in ventilation to CFC-12 measurements made during the
WOCE program in the 1990 s and $\mathrm{SF}_{6}$ measurements made along the same sections in the mid- to late 2000s as part of the CLIVAR repeat hydrography program. We focus this comparison on four locations that were sampled as part of the previously mentioned programs (Table 1): these areas were selected because there are $\mathrm{CFC}-12$ and $\mathrm{SF}_{6}$ data with suitable time lag and because discussions of ventilation in these regions are available in the literature (see next section).

\subsection{South Pacific Ocean (line P18)}

[11] We first discuss the subtropical South Pacific Ocean section (line P18). Figure 3, top row, shows vertical profiles of the concentrations (in partial pressure, ppt) of CFC-12 for both the historic (1994) and modern (2007) data sets, for samples between $33^{\circ} \mathrm{S}$ and $37^{\circ} \mathrm{S}$. Data from several stations within a region along a repeat line are averaged on density surfaces and plotted versus potential density to reduce small-scale temporal and spatial variability. There is an increase in CFC-12 between 1994 and 2007 at all depths. To examine whether this increase is consistent with steady

Table 1. Data used in Figure 3

\begin{tabular}{|c|c|c|c|}
\hline Obser & & & \\
\hline Line & Area & Historic cruise & Modern cruise \\
\hline P18 & South Pacific $33-37^{\circ} \mathrm{S} 103^{\circ} \mathrm{W}$ & 31DSCGC94 1994 & 33RO20071215 2007 \\
\hline I05 & South Indian $32^{\circ} \mathrm{S} 90-100^{\circ} \mathrm{E}$ & 316 N145 71995 & 33RR20090320 2009 \\
\hline A16 & North Atlantic $35-40^{\circ} \mathrm{N} 17-24^{\circ} \mathrm{W}$ & $32 \mathrm{OC} 202^{-} 11988$ & 06МT200403112004 \\
\hline $\mathrm{P} 16 \mathrm{~N}$ & North Pacific $19-31^{\circ} \mathrm{N} 152^{\circ} \mathrm{W}$ & 31DSCGC91-1 1991 & 3250200602132006 \\
\hline
\end{tabular}

Column 1 is the WOCE name of the repeat line. Column 2 is the area used for averaging the data in Figure 3. Columns 3 and 4 give the name (Expocode) of the cruise and the year the area was occupied. Data are available at http://cchdo.ucsd.edu/. 

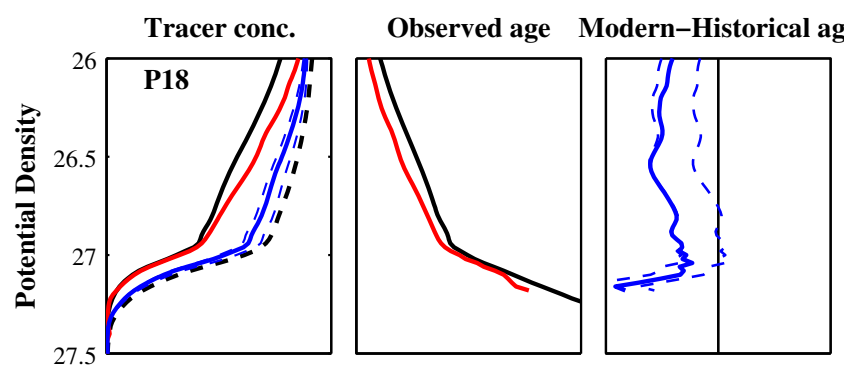

Modelled age
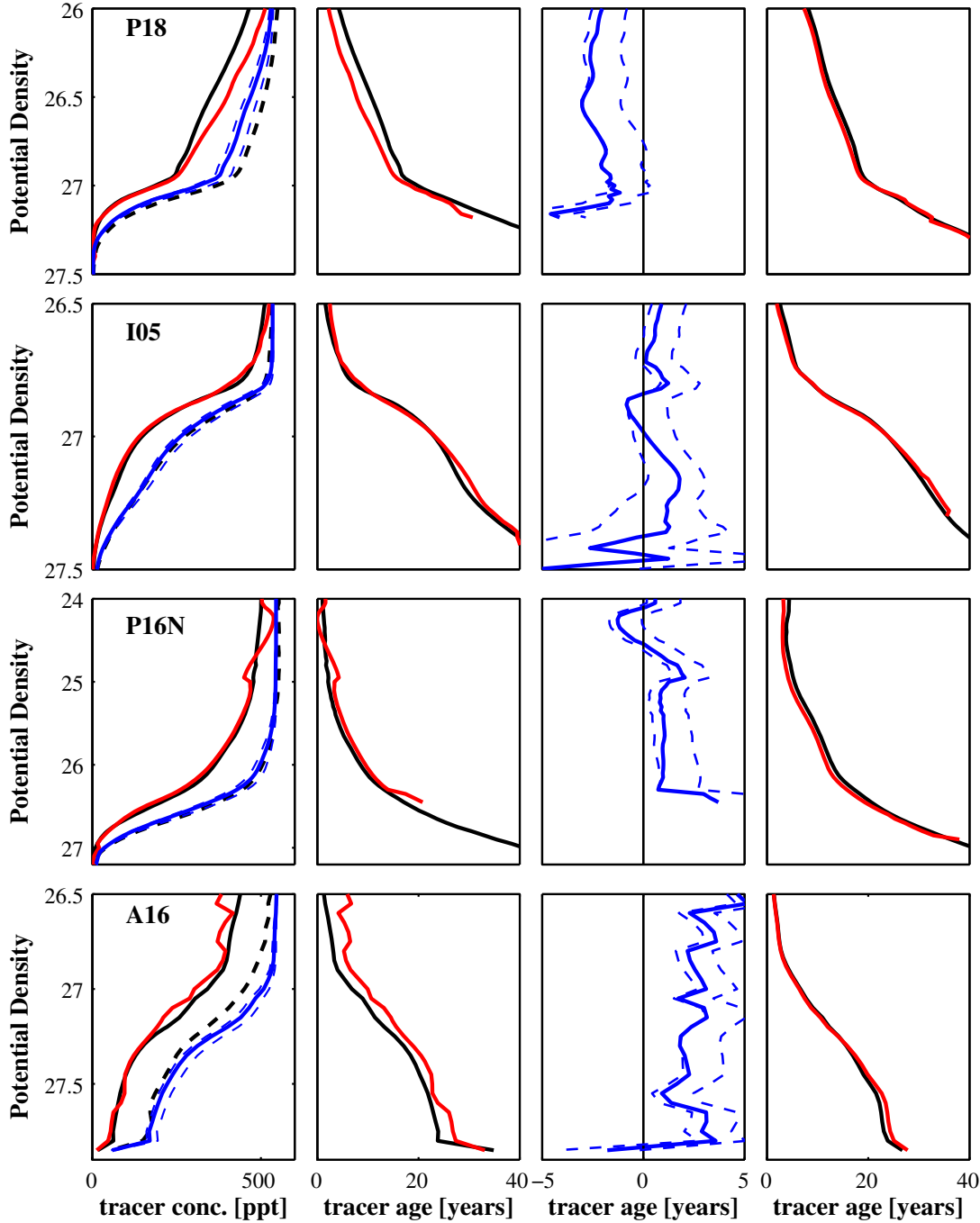

Figure 3. Left panels show averaged pCFC-12 (historic_-black solid line, modern_-black dashed line) and (modern) pSF 6 (red) concentrations. Predicted pCFC-12 concentrations for the modern repeat (calculated from the historic observations using IG TTD) is shown in blue; solid line $\Delta / \Gamma=1.0$, dashed lines for $\Delta / \Gamma=0.6$ and 1.4 , respectively. The $\mathrm{SF}_{6}$ data in the left panels have been multiplied by 89 to better match the historic CFC-12 concentrations. The second column shows the comparison of historic CFC-12 (black) and modern $\mathrm{SF}_{6}$ tracer ages (red) from observations. The third column shows the difference between modern $\left(\mathrm{SF}_{6}\right)$ and historic $(\mathrm{CFC}-12)$ tracer ages with the uncertainties from the measurements $(5$ and $0.1 \mathrm{ppt}$ for $\mathrm{CFC}-12$ and $\mathrm{SF}_{6}$, respectively, uncertainties from Figure $2 \mathrm{~b}$ and bias from Figure $2 \mathrm{a}$ ) showed with dashed lines. The fourth column shows profiles of historic CFC-12 (black) and modern $\mathrm{SF}_{6}$ (red) ages from the DeVries and Primeau [2011] model for the same area as the observations. The data in the first row are from the subtropical South Pacific Ocean; the second row is from the subtropical south Indian Ocean; the third row is from the subtropical north Pacific; the fourth row is the subtropical north Atlantic (see Table 1 for details). The model results are for 1994 and 2008 for rows 1 and 2, 1991 to 2006 for row 3, and 1988 to 2004 for row 4.

transport, we compared the observed increase with that predicted using IG TTDs. The blue curves in the first column show the TTD predictions of CFC-12 in 2007, for a range of $\Delta / \Gamma$ ratios. These predicted concentrations are significantly lower than the observed CFC-12 concentrations, from below the mixed layer down to a potential density of $\sim 27.0$ (approximately 200-600 meters depth). This suggests that for these waters the ventilation rate has increased (water mass age has decreased) between 1994 and 2007 [e.g., Waugh et al., 2013].

[12] This conclusion is, however, based on the assumption that the flow can be modeled by an IG TDD with $\Delta / \Gamma \sim 1$.
The new $\mathrm{SF}_{6} / \mathrm{CFC}-12$ method does not require this assumption. The second and the third columns in Figure 3 compare the tracer ages calculated from the historic CFC-12 and modern $\mathrm{SF}_{6}$ data for the same section. The $2007 \mathrm{SF}_{6}$ age is significantly lower than the 2004 CFC-12 age and supports the conclusion of an increase in ventilation rate between 1994 and 2007. In the deeper part of the water column, the analysis suggests steady circulation, although as the water is becoming older the $\mathrm{SF}_{6}$ measurements are more uncertain (see dashed lines in the third column if Figure 3) and finally below the analytical quantification limit. The fourth column compares vertical profiles of tracer ages from the 
steady-state model; for all four regions, there is excellent agreement between the $\mathrm{CFC}-12$ and $\mathrm{SF}_{6}$ tracer ages.

\subsection{South Indian Ocean (line I05)}

[13] Temporal variability for this part of the Indian Ocean has been reported on previously [e.g., Bindoff and McDougall, 2000; McDonagh et al., 2005]. As for the south Pacific section, there is an increase in CFC-12 between the two occupations. However, for this section, the observed increase is captured by the steady TTD model. This suggests that there has not been a significant change in the ventilation rate for this location between 1995 and 2009. Again, we can use the new $\mathrm{SF}_{6} / \mathrm{CFC}-12$ method to test this. As shown in Figure 3, the $2009 \mathrm{SF}_{6}$ age agrees well with the 2005 CFC-12 age and supports the conclusion of no change in ventilation rate between 1995 and 2009. However, Waugh et al. [2013] found changes in ventilation on a meridional section along $\sim 90^{\circ} \mathrm{E}$ (I08) between 1994/95 and 2007. Similarly, an analysis of changes in ventilation at this location based on TTDs determined from CFC-12 measurements from three occupations of the I05 line [Álvarez et al., 2011] reveals constant ventilation in the water column above the potential density of 26.9 , but with variations in mean age deeper in the water column with alternating ventilation ages over time, increasing age between 1987 and 1995 but decreasing age between 1995 and 2002 and between 1987 and 2002. This results from a forward ocean model (CCSM3.1), indicating influence of multi-decadal variability on the ventilation in this region, likely associated with the Southern Annular Mode [Álvarez et al., 2011]. Variability in ocean ventilation in the CCSM3 model is also discussed by Bryan et al. [2006], where they conclude that observations of tracers can detect secular changes in ocean circulation but that decadal variability might alias observationally based estimates of ocean ventilation.

\subsection{North Pacific Ocean (line P16N)}

[14] Section P16N in the North Pacific was occupied in 1991 as part of WOCE and repeated as part of the CLIVAR program in 2006. The 2006 occupation included the first $\mathrm{SF}_{6}$ measurements made as part of the CLIVAR program and the $\mathrm{SF}_{6}$ coverage was relatively sparse along the section. As with the other sections discussed, there is an increase in CFC-12 concentrations between the two occupations of this section (Figure 3). The CFC-12 tracer ages in 1991 along $\mathrm{P} 16 \mathrm{~N}$ are in relatively good agreement with the $\mathrm{SF}_{6}$ tracer ages in 2006 (Figure 3), which is consistent with no significant overall change in ventilation over this time interval.

[15] Sonnerup et al. [2008] used a simple one-dimensional ventilation model constrained by 1991 CFC-12 and 2006 CFC-12 and $\mathrm{SF}_{6}$ tracer ages to investigate possible changes in ventilation rates along the $\mathrm{P} 16 \mathrm{~N}$ section over this time interval. Their results are consistent with no net change during this interval (1991-2006), in agreement with the results from the $\mathrm{CFC}-12 / \mathrm{SF}_{6}$ time lag method presented here. This does not, however, preclude variability within this time interval, and there is evidence of both slowdowns in the overturning of the subtropical cell in this region in the mid-1980s to mid-1990s [McPhaden and Zhang, 2002] followed by increases since the 1990s [Zhang and McPhaden, 2006]. Studies using a two-dimensional diagnostic model to estimate the effects of mixing on CFC tracer ages [Mecking et al., 2004; Mecking et al., 2006] indicate that the relatively large tracer age increases observed from $40^{\circ} \mathrm{N}$ to $45^{\circ} \mathrm{N}$ along the P16N section between 1991 and 1997 are consistent with a slowdown in ventilation over this period. Such variability might not be detected over a larger time interval (e.g., 1991-2006).

\subsection{North Atlantic Ocean (line A16N)}

[16] For this area in the subtropical North Atlantic Ocean, we used data from a repeat of the A16N line in 1998 and a cruise along a quasi-zonal section in 2004. The significant temporal variability of convection and circulation in the north Atlantic Ocean has been reported by several authors as has temporal changes in tracer concentrations [e.g., Tanhua et al., 2006; Steinfeldt et al., 2009; Rhein et al., 2011]. The observations suggest that there has been a slowdown of the ventilation in the potential density range from 26.5 to approximately 27.7 . This is supported by both CFC-12 observations during the two repeat occupations (Figure 3) and by the $\mathrm{CFC}-12 / \mathrm{SF}_{6}$ method (Figure 3). Our analysis supports previous observations of temporal variability in the North Atlantic Ocean and demonstrates the utilization of the $\mathrm{CFC}-12 / \mathrm{SF}_{6}$ method to detect changes in ventilation.

\section{Conclusion}

[17] We have demonstrated a new method to detect changes in ocean ventilation from repeat hydrography and measurements of transient tracers. This method takes advantage of the similar atmospheric increase rates of CFC-12 and $\mathrm{SF}_{6}$ (with a lag of approximately $14-15$ years) so that direct comparison of the tracer ages can be made without requiring the use of a model to account for mixing. The advantage of this method is that it involves few assumptions and can thus be seen as a reference method for those areas of the ocean where this method is applicable, that is, along repeat sections where "historic" CFC-12 and "modern" $\mathrm{SF}_{6}$ measurements exist with roughly the right time lag. An analysis of data from the South Pacific and North Atlantic Oceans suggests changes in ventilation in these oceans, whereas a change in ventilation is not needed to explain data from the south Indian and the north Pacific Oceans.

[18] The disadvantage of this method is that there are relatively few places in the ocean where repeat data sets have been collected that meet these conditions. However, there are increasing number of $\mathrm{SF}_{6}$ measurements being performed on repeat lines so that one can expect that more areas will become available for similar comparisons in the future. Although the recent atmospheric history of CFC-12 is deviating from that $\mathrm{SF}_{6}$ in a way that will make it difficult to evaluate the most recently ventilated waters with this method, there will still be a "window" of tracer ages for future cruises where this method will have moderate or small biases only, that is, for waters ventilated in the period from $\sim 1970$ to $\sim 2000$. The combination of CFC-12 and $\mathrm{SF}_{6}$ measurements has the additional advantage that changes in ventilation for the upper ocean, that is, the recently ventilated thermocline, can be established. This is difficult to do with the modern measurements of CFC-12 alone due to the almost steady atmospheric concentration of CFC-12 since the early 1990s. 


\section{TANHUA ET AL.: CHANGES IN OCEAN VENTILATION}

[19] Acknowledgments. The authors thank Tim DeVries and Francois Primeau for the use of model data.

\section{References}

Álvarez, M., T. Tanhua, H. Brix, C. Lo Monaco, N. Metzl, E. L. McDonagh, and H. L. Bryden (2011), Decadal biogeochemical changes in the subtropical Indian Ocean associated with Subantarctic Mode Water, J. Geophys. Res., 116(C9), C09016, doi: 10.1029/2010jc006475.

Bindoff, N. L., and T. J. McDougall (2000), Decadal changes along an Indian Ocean section at $32^{\circ} \mathrm{S}$ and their interpretation, J. Phys. Oceanogr., 30(6), 1207-1222.

Bryan, F. O., G. Danabasoglu, P. R. Gent, and K. Lindsay (2006), Changes in ocean ventilation during the 21 st Century in the CCSM3, Ocean Modelling, 15(3-4), 141-156, doi: 10.1016/j.ocemod.2006.01.002.

Bullister, J. L. (2011), Atmospheric CFC-11, CFC-12, CFC-113, CCl4 and SF6 Histories (1910-2011), edited, Carbon Dioxide Information Analysis Center, http://cdiac.ornl.gov/oceans/new_atmCFC.html.

Bullister, J. L., and D. P. Wisegarver (2008), The shipboard analysis of trace levels of sulfur hexafluoride, chlorofluorocarbon-11 and chlorofluorocarbon-12 in seawater, Deep-Sea Res. I, 55(8), 1063-1074.

Bullister, J. L., D. P. Wisegarver, and F. A. Menzia (2002), The solubility of sulfur hexafluoride in water and seawater, Deep-Sea Res. I, 49(1), 175-187.

DeVries, T., and F. Primeau (2011), Dynamically and observationally constrained estimates of water-mass distributions and ages in the global ocean, J. Phys. Oceanogr., 41(12), 2381-2401, doi: 10.1175/jpo-d-1005011.1 .

Fine, R. A. (2011), Observations of CFCs and $\mathrm{SF}(6)$ as Ocean tracers, Annual Review of Marine Science, 3(3), 173-195,

Freing, A., D. W. R. Wallace, T. Tanhua, S. Walter, and H. W. Bange (2009), North Atlantic production of nitrous oxide in the contex of changing atmospheric levels, Global Biogeochem Cycle, 23, doi: 10.1029/2009GB003472.

Gammon, R. H., J. Cline, and D. P. Wisegarver (1982), Chluorofluoromethanes in the Northeast Pacific Ocean: Measured vertical distribution and application as transient tracers of upper ocean mixing, J. Geophys. Res., 87(C12), 9441-9454.

Haine, T. W. N., and K. J. Richards (1995), The influence of the seasonal mixed layer on oceanic uptake of CFCs, J. Geophys. Res., 100(C6), $10727-10744$

Hall, T. M., and T. W. N. Haine (2002), On Ocean Transport Diagnostics: The Idealized Age Tracer and the Age Spectrum, J. Phys. Oceanogr., 32, 1987-1991.

Law, C. S., and A. J. Watson (2001), Determination of Persian Gulf Water transport and oxygen utilisation rates using $\mathrm{SF}_{6}$ as a novel transient tracer, Geophys. Res. Lett., 28(5), 815-818.

McDonagh, E. L., H. L. Bryden, B. A. King, R. J. Sanders, S. A. Cunningham, and R. Marsh (2005), Decadal changes in the south Indian Ocean thermocline, J. Climate, 18(10), 1575-1590.
McPhaden, M. J., and D. Zhang (2002), Slowdown of the meridional overturning circulation in the upper Pacific Ocean, Nature, 415, 603-608. Mecking, S., M. J. Warner, and J. L. Bullister (2006), Temporal changes in pCFC-12 ages and AOU along two hydrographic sections in the eastern subtropical North Pacific, Deep-Sea Res. I, 53(1), 169-187.

Mecking, S., M. J. Warner, C. E. Greene, S. L. Hautala, and R. E. Sonnerup (2004), Influence of mixing on CFC uptake and CFC ages in the North Pacific thermocline, J. Geophys. Res., 109(C7), doi: 10.1029/ 2003JC001988.

Rhein, M., D. Kieke, S. Hüttl-Kabus, A. Roessler, C. Mertens, R. Meissner, B. Klein, C. W. Böning, and I. Yashayaev (2011), Deep water formation, the subpolar gyre, and the meridional overturning circulation in the subpolar North Atlantic, Deep-Sea Res. II Top. Stud. Oceanogr., 58(17-18), 1819-1832, doi: 10.1016/j.dsr2.2010.10.061.

Sonnerup, R. E. (2001), On the relations among CFC derived water mass ages, Geophys. Res. Letters, 28(9), 1739-1742.

Sonnerup, R. E., J. L. Bullister, and M. J. Warner (2008), Improved estimates of ventilation rate changes and $\mathrm{CO}(2)$ uptake in the Pacific Ocean using chlorofluorocarbons and sulfur hexafluoride, J. Geophys. Res., 113(C12), C12007.

Steinfeldt, R., M. Rhein, J. L. Bullister, and T. Tanhua (2009), Inventory changes in anthropogenic carbon from 1997-2003 in the Atlantic Ocean between 20 degrees S and 65 degrees N, Global Biogeochem Cycle, 23 , GB3010, doi:10.1029/2008GB003311.

Tanhua, T., A. Biastoch, A. Körtzinger, H. Lüger, C. Böning, and D. W. R. Wallace (2006), Changes of anthropogenic CO2 and CFCs in the North Atlantic between 1981 and 2004, Global Biogeochem Cycle, 20, GB4017, doi: 10.1029/2006GB002695.

Tanhua, T., K. A. Olsson, and E. Fogelqvist (2004), A first study of $\mathrm{SF}_{6}$ as a transient tracer in the Southern Ocean, Deep-Sea Res. II, 51, 2683-2699.

Tanhua, T., D. W. Waugh, and D. W. R. Wallace (2008), Use of SF6 to estimate anthropogenic carbon in the upper ocean, J. Geophys. Res. Oceans, 113, C04037.

Walker, S. J., R. F. Weiss, and P. K. Salameh (2000), Reconstructed histories of the annual mean atmospheric mole fractions for the halocarbons CFC-11, CFC-12, CFC-113 and carbon tetrachloride, J. Geophys. Res., 105(C6), 14285-14296,

Warner, M. J., and R. F. Weiss (1985), Solubilities of chlorofluorocarbons 11 and 12 in water and sea water, Deep-Sea Res., 32(12), 1485-1497.

Waugh, D. W., T. M. Hall, and T. W. N. Haine (2003), Relationship among tracer ages, J. Geophys. Res., 108(C5), doi: 10.1029/2002JC001325.

Waugh, D. W., T. M. Hall, B. I. McNeil, R. Key, and R. J. Matear (2006), Anthropogenic $\mathrm{CO} 2$ in the Oceans estimated using transit-time distributions, Tellus, 58B, 376-389, doi: 10.1111/j.1600-0889.2006.00222.x.

Waugh, D. W., F. Primeau, T. DeVries, and M. Holzer (2013), Recent changes in the ventilation of the southern oceans, Science, 339, 568.

Zhang, D. X., and M. J. McPhaden (2006), Decadal variability of the shallow Pacific meridional overturning circulation: Relation to tropical sea surface temperatures in observations and climate change models, Ocean Modelling, 15(3-4), 250-273, doi: 10.1016/j.ocemod.2005.12.005. 